MATEC Web of Conferences 37, 01010 (2015)

DOI: $10.1051 /$ matecconf $/ 20153701010$

(C) Owned by the authors, published by EDP Sciences, 2015

\title{
PROSPECTS OF USING FLY ASH PRODUCED AT KEMEROVO STATE DISTRICT POWER STATION
}

\author{
A.R. Bogomolov ${ }^{1,}$,, E.Yu Temnikova ${ }^{3}$, S.A. Shevyrev ${ }^{2}$, A.V. Poltavets ${ }^{3}$ and A.S. Sysolyatin ${ }^{3}$ \\ ${ }^{1}$ Kutateladze Institute of Thermophysics SB RAS, 630090 Novosibirsk, Russia \\ ${ }^{2}$ Tomsk Polytechnic University, 634050 Tomsk, Russia \\ ${ }^{3}$ Kuzbass State Technical University named after T.F. Gorbachev, 650000 Kemerovo, Russia
}

Abstract. Experimental results of fractional and chemical composition fly ash from Kemerovo SDPS (Russia, Kuzbass) are presented. The technological scheme of complex utilization of fly ash and its economic characteristics is given.

\section{Introduction}

According to data of Siberian Generating Company (SGC), enterprises of Kuzbass Branch of GTS produces annually about 2 million tons of ash on the ash dumps, and their total amount reaches 80 million tons. Waste energy is traditionally utilized in special depositories - ash dumps and, along with the loss of lands, this leads to intensification of uncontrolled migration of wastes into the environment.

In Kemerovo region, the generating companies started developing a package of measures to increase useful application of ash and slag waste (ASW) and their involvement into the economy. For example, a light fraction is collected from the water surface of ash dumps of Belovskaya SDPS and Tom-Usinsk SDPS, it is packed in the soft specialized containers and is processed into the high-quality product - aluminum silicate microspheres, using the unique equipment.

Most part of utilized ASW can be applied for production of construction materials, construction of roads and land revegetation, including mine working; however, the main part of ASW is used without additional processing.

\section{Problem statement}

The purpose of the current study is to develop a comprehensive approach to processing the fly ash into the magnetic, nonmagnetic, and "light" faction demanded by industry.

The task of this work is investigation of dispersed and chemical composition of fly ash and its fractions for processing into the valuable components.

\section{Result and discussion}

As a result of separation of fly ash from Kemerovo SDPS, the weight average content of fractions was obtained: for the nonmagnetic one $-92.3 \%$, for magnetic $-4.5 \%$ and "light" (microspheres) $-1.8 \%$. The main part of the fly ash (66\%) has the size smaller than $50 \mu \mathrm{m}$.

The chemical compositions of magnetic and non-magnetic fractions of fly ash were determined (Table. 1). In the magnetic and nonmagnetic fractions, silicon oxide ( $\mathrm{SiO})$ has the major percentage of the total weight. According to [1, 2], the content of this component is in the range of $46-62 \%$.

The sieve test of microspheres has been performed; it showed that the basic content of the microspheres $88.8 \%$ corresponds to three sizes of $90,130,180 \mu \mathrm{m}$ (90-180 microns). To produce the microspheres, it is sufficient to disperse fly ash through the sieve with the mesh size of 80 and $180 \mu \mathrm{m}$. We assume that the conditions of microspheres formation during the combustion process depend mainly on the pulverization process. Fineness of coal dust affects the size of the beads formed in the boiler furnace.

\footnotetext{
${ }^{a}$ Corresponding author: barom@mail.kuzstu.ru
}

This is an Open Access article distributed under the terms of the Creative Commons Attribution License 4.0, which permits unrestricted use, distribution, and reproduction in any medium, provided the original work is properly cited. 


\section{MATEC Web of Conferences}

Table 1. Chemical composition of fly ash

\begin{tabular}{|c|c|c|}
\hline \multirow{2}{*}{ Component } & \multicolumn{2}{|c|}{ Content, \% } \\
\cline { 2 - 3 } & Non-magnetic fraction & Magnetic fraction \\
\hline $\mathrm{Na}_{2} \mathrm{O}$ & 1.76 & 1.45 \\
\hline $\mathrm{MgO}$ & 2.02 & 3.21 \\
\hline $\mathrm{Al}_{2} \mathrm{O}_{3}$ & 22.00 & 16.28 \\
\hline $\mathrm{SiO}_{2}$ & 58.14 & 44.52 \\
\hline $\mathrm{P}_{2} \mathrm{O}_{5}$ & 0.58 & 0.48 \\
\hline $\mathrm{SO}_{3}$ & 0.41 & 0.48 \\
\hline $\mathrm{K}_{2} \mathrm{O}$ & 2.50 & 1.66 \\
\hline $\mathrm{CaO}$ & 5.37 & 6.06 \\
\hline $\mathrm{TiO} \mathrm{O}_{2}$ & 0.84 & 0.59 \\
\hline $\mathrm{MnO}$ & 0.06 & 0.09 \\
\hline $\mathrm{Fe} \mathrm{O}_{3}$ & 6.00 & 25.01 \\
\hline $\mathrm{BaO}$ & 0.33 & 0.20 \\
\hline
\end{tabular}

Table 2. Unburned carbon

\begin{tabular}{|c|c|}
\hline Sample, $\boldsymbol{\mu m}$ & Share of unburned organic mass of fuel, $\%$ \\
\hline$<50$ & 0.7387 \\
\hline $50-63$ & 1.6987 \\
\hline $63-80$ & 1.5196 \\
\hline $80-100$ & 2.0951 \\
\hline $100-160$ & 5.2857 \\
\hline $160-200$ & 4.8478 \\
\hline$>200$ & 2.2152 \\
\hline
\end{tabular}

To determine the mechanical underburning, the fly ash was separated into fractions, and each fraction was analyzed (Table 2). Mechanical underburning of fuel includes a content of fuel carbon in the ash entrained by flue gases. Since $84 \%$ of fly ash consists of the particles smaller than $80 \mu \mathrm{m}$, thus, a proportion of unburned carbon in ash is concentrated in this fraction and makes up about $4 \%$. It is reasonable to take the unburned particles from ash because they are undesirable component, which decreases the quality of constructions.

The technological scheme of the complex for fly ash utilization (Fig. 1) is developed, and the basic equipment is selected. The suggested complex for fly ash utilization is a set of technological equipment, which can process recycled ash into 3 fractions. In general, the entire process is carried out in 4 stages: selection of dry fly ash; ash transportation to the place of utilization; separation of initial material into 3 fractions; packaging of the final product.

Ash from electric filter hopper 1 is collected into collecting hopper 2, then it uniformly fed into pipeline 3 (BShGD, $d=$ $219 \times 20 \mathrm{~mm}, l=100 \mathrm{~m}$ ). To transport the bulk material, the vacuum system is used; the main element of this system is vapor ejector 5, rarefying the pneumatic system. Valve 15 regulates air supply into the system. Air transports ash particles in suspension through pipeline 3 to dust collector 4 (VZP-M-450), where it is deposited. Further, dust-laden air is directed to the second stage of processing by two centrifugal cyclones 6 (TSN11-630 and UTSM-38-800), then, the purified air mixed with vapor is discharged through the chimney into the atmosphere. Ash from the dust collector 4 and cyclones 6 is dumped into hopper 9, where the intermediate accumulation of initial material occurs. Ash is dumped through a feeder onto the belt conveyor 7 (LT-400), magnetic separator 8 (RCYD-5) is installed above this belt; it collects magnetic fractions from a moving line. Passing magnetic separator 8 , the non-magnetic fraction is dumped into receiving hopper 9, then the raw material is supplied to vibrating sieve 10 (SWECO MX 60). The separated fractions are accumulated in intermediate hoppers 11, 12 and 13; under each of these hoppers, there is weighting-and-filling machine 14 (DF-OB) for the automatic packaging of each fraction in special "Big bags".

The yield of fly ash from the boiler E-420-14-550 (TP-87-1) at Kemerovo State District Power Station is about 10 t/h. This complex allows processing of approximately 61,320 tons of fly ash per year in the scale of Kemerovo SDPS and reduces the costs of payments by 858 thousand rubles/year for allocation of ASW on the ash dump at the rate of payments of 14 rubles/t. It will also improve the situation in the direction of reducing the volume of ash stored at the ash dump of the station, increasing the period of the existing ash dump exploitation.

The complex for fly ash utilization will be located at the territory of Kemerovo SDPS and the construction will be made from the zero cycle. The estimated cost of the whole complex with consideration of the installed equipment (and construction of the sandwich panels) will be about 9 million rubles. For the following market values of each fraction, "light" - 20000 rub./t; nonmagnetic - $800 \mathrm{rub} . / \mathrm{t}$; magnetic - $5000 \mathrm{rub} . / \mathrm{t}$ - the income will be about 78 million rubles, the net profit of the complex will be 67.5 million rubles, the payback period is 1.5 months. Every invested ruble will bring a profit of 7.63 rubles. 


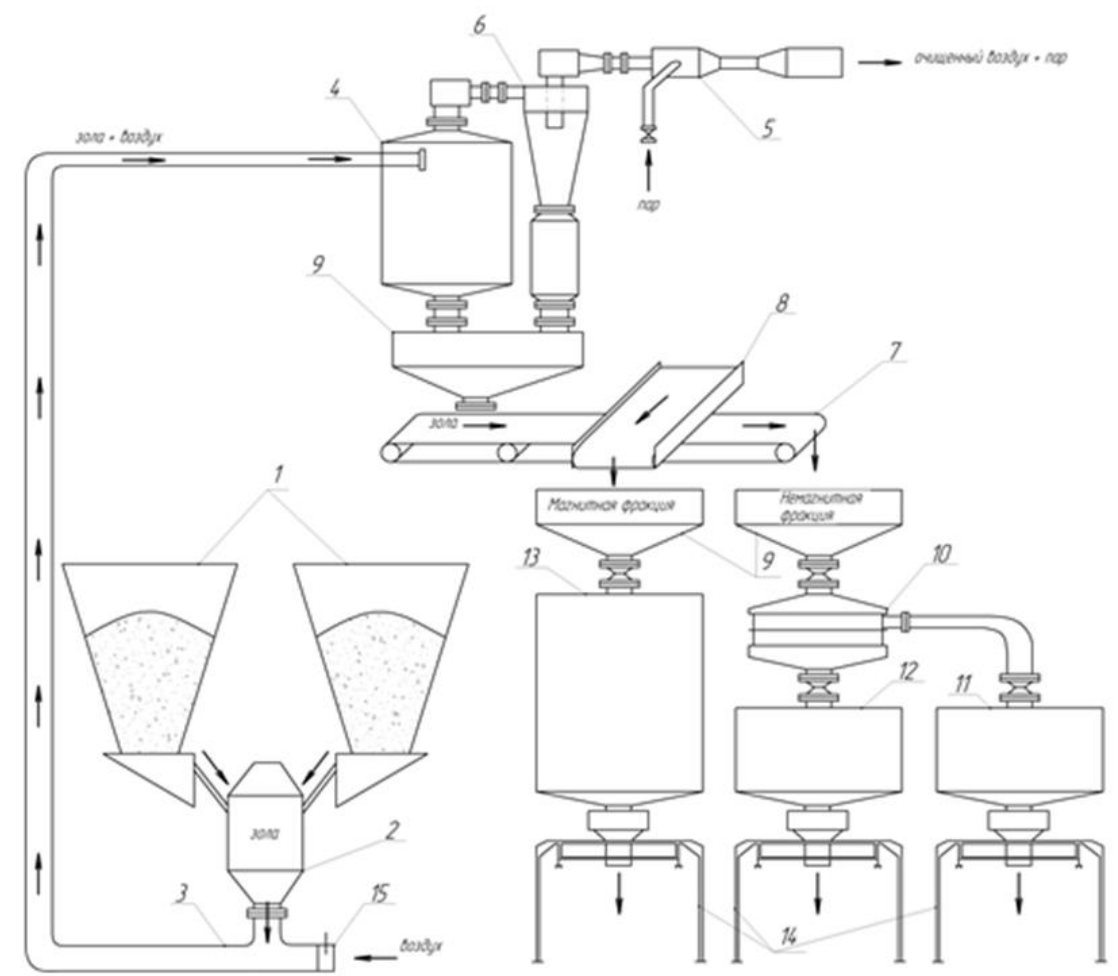

Figure 1. Flow chart of setup for fly ash utilization: 1 - hopper of electric filter; 2 - collecting hopper; 3 - pneumatic ash line; 4 - dust collector; 5 - vapor ejector; 6 - cyclones; 7 - belt conveyor; 8 - magnetic separator; 9 - receiving hopper; 10 - round vibrating sieve; $11,12,13$ intermediate hoppers; 14 - weighting-and-filling machine; 15 - valveю

\section{Conclusion}

According to the research of the market for fly ash, it can be said that after deep processing of ashes the end separation products are of a higher demand in various sectors of industry and agriculture than the original product.

The work was financially supported in the framework of agreement No. 14.583.21.0004 Federal Target Program, RFMEF158314X0004.

\section{References}

1. Fedorova N.V., Shaforost D.A. Thermal Engineering, 1, 51 (2015)

2. Shishelova T.I., Samuseva T.I. Proc. Conference "The success of modern natural science", 11, 77 (2007) 